\section{Präimplantationsdiagnostik (PID)}

\section{J. Arnemann}

Abteilung Molekulargenetik, Labor Dr. Wisplinghoff, Köln, Deutschland

\section{Synonym(e) PID-Diagnostik}

Englischer Begriff pre-implantation diagnostics (PID)

Definition Die Präimplantationsdiagnostik gehört zur Reproduktionsmedizin und wird eingesetzt, um im Zusammenhang mit einer In-vitro-Fertilisation (IVF) die befruchtete Eizelle bzw. den noch nicht implantierten Embryo auf mögliche genetische Defekte hin zu testen.

Beschreibung Bei der Präimplantationsdiagnostik stehen im Vordergrund das Screening auf Aneuploidien und das Testen auf bekannte familiär segregierende Mutationen für schwerwiegende genetische Erkrankungen.

Die Methode unterlag in den vergangenen Jahren verschiedenen Modifikationen, teilweise auch abhängig von den rechtlichen Rahmenbedingungen. So wurde in Deutschland in der Anfangsphase die Polkörper-Diagnose durchgeführt, bei der nach der zweiten meiotischen Teilung der Polkörper der Eizelle noch vor der Verschmelzung der männlichen und weiblichen Vorkerne, also präzygotisch, eine Analyse auf Aneuploidien, die Vererbung maternaler Chromosomentranslokationen oder auf eine maternal vererbte Mutation für eine schwerwiegende Erbkrankheit getestet wurde. Hierdurch wurden die Einschrän- kungen des deutschen Embryonenschutzgesetzes respektiert. In anderen Ländern verfolgte man zeitgleich eine Präimplantationsdiagnostik, bei der man dem Embryo im 4- bis 8-Zell-Stadium eine Zelle zur weitergehenden Diagnostik entnahm (Embryobiopsie). Die Diagnostik wurde ebenfalls weiterentwickelt und verfeinert durch Arraytechniken oder auch durch PCR-basierte Vervielfältigung der genomischen DNA. Aktuell testet man Zellen aus der inneren Zellmasse (IC) des Blastozystenstadiums, die sich potenziell zum Embryo entwickeln, im Gegensatz zu den äußeren Zellen, die sich zu Trophoblasten bzw. Plazenta entwickeln. Die Blastozysten werden nach erfolgter Analyse implantiert (Embryotransfer) oder gegebenenfalls auch kryokonserviert.

Es muss darauf hingewiesen werden, dass diese Methode zu einem gewissen Anteil fehleranfällig ist und die Sicherheit des Ergebnisses mit 90-95 \% angegeben wird. Als Fehler werden z. B. Kontaminationen mit Fremd-DNA oder eine Allel-Dropout (s. > Allelic Dropout (Allelausfall)) beobachtet. In Deutschland ist die Präimplantationsdiagnostik ethisch heftig umstritten und weitestgehend verboten. Sie ist nur zulässig, wenn aufgrund der genetischen Veranlagung der Eltern beim Kind eine schwerwiegende Erbkrankheit mit geringer Lebenserwartung oder fehlender Behandlungsmöglichkeit zu erwarten ist.

\section{Literatur}

Richter G (2004) Präimplantationsdiagnostik: Möglichkeit zur Erfüllung des Kinderwunsches. Dtsch Arztebl 101(6):A-327/B-280/C-273 